\title{
Target Sign: Endoscopic Sign of the Colonic Perforation
}

\author{
Target Sign: Sinal Endoscópio de Perfuração
}

Juliana Moura COSTA $₫ 1$, João Bruno SOARES 1

Acta Med Port 2017 Jun;30(6):500-500 - https://doi.org/10.20344/amp.8791

Keywords: Colon/injuries; Colonoscopy/adverse effects; Intestinal Mucosa/injuries; Intestinal Perforation

Palavras-chave: Cólon/lesões; Colonoscopia/efeitos adversos; Mucosa Intestinal/lesões; Perfuração Intestinal
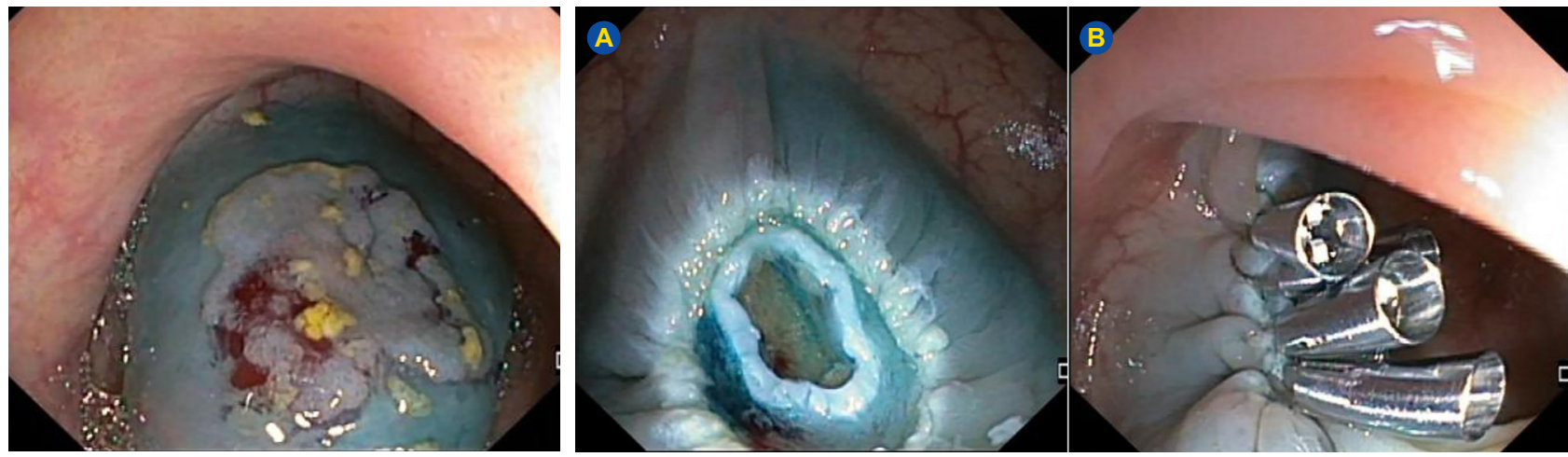

Figure 1 - Endoscopic image of the $20 \mathrm{~mm}$ Figure 2 - A: The 'target sign' was observed after endoscopic mucosal resection of non-granular laterally spreading tumor in the the colonic lesion; B: The defect in the muscularis propria ('target sign') was closed by descending colon endoscopic clipping.

A 68-year-old man underwent an en bloc endoscopic mucosal resection (EMR) of a $20 \mathrm{~mm}$ non-granular laterally spreading tumor, type 0 -lla of the Paris classification, in the descending colon (Fig. 1).

During the procedure, unintentional resection of the muscularis propria ('target sign') was observed immediately (Fig. 2A); the defect was closed by endoscopic clipping using four clips (Fig. 2B); no clinical or radiologic signs of the pneumoperitoneum were present. The patient was discharged two days later, completely asymptomatic.

Colonic perforation may occur in $2 \%-10 \%$ of patients undergoing colonic EMR and endoscopic submucosal dissection. ${ }^{1}$ Commonly, diagnosis is delayed and depends on clinical and radiologic findings. ${ }^{2}$

The 'target sign' white center (muscularis propria and/or serosa) with surrounding stained area (stained submucosa), ${ }^{1}$ is an endoscopic marker for resection of the muscularis propria and indicates a potential colonic perforation. ${ }^{3}$

Recognition of the 'target sign' allows prompt endoscopic diagnosis and management of potential colonic perforation..$^{1,3}$

\section{REFERENCES}

1. Kantsevoy SV. The target sign: a new weapon for early diagnosis of colonic perforation during EMR. Gastrointest Endosc. 2011;73;86-8.

2. Hainaux B, Agneessens E, Bertinotti R, De Maertelaer V; Rubesova E Capelluto E, et al. Accuracy of MDCT in predicting site of gastrointestinal tract perforation. AJR Am J Roentgenol. 2006;187:1179-83.

3. Swan MP, Bourke MJ, Moss A, Williams SJ, Hopper A, Metz A. The target sign: an endoscopic marker for the resection of the muscularis propria and potential perforation during colonic endoscopic mucosal resection. Gastrointest Endosc. 2011;73:79-85.

\footnotetext{
1. Departamento de Gastroenterologia. Hospital de Braga. Braga. Portugal.

$\triangle$ Autor correspondente: Juliana Moura Costa. julianamcosta87@gmail.com

Recebido: 05 de fevereiro de 2017 - Aceite: 03 de maio de 2017 | Copyright $\odot$ Ordem dos Médicos 2017
} 